\title{
Apatit - Wollastonit Cam Üretimi ve Temperlemenin Sertlik Üzerine Etkisi
}

\author{
${ }^{* 1}$ Fatih Çalışkan, ${ }^{2}$ Zafer Tatlı ve ${ }^{3}$ Erhan İbrahimoğlu, ${ }^{4}$ Adem Demir \\ 1,2,3,4Sakarya Uygulamalı Bilimler Üniversitesi, Esentepe Kampüsü, Sakarya, Türkiye
}

Özet

$\mathrm{Bu}$ çalışmada, Apatit - wollastonit içeren biyoaktif cam-seramikler üretilmiş ve karakterizasyonu yapılmıştır. Üretimi için, $\mathrm{CaO}, \mathrm{SiO} 2, \mathrm{P} 2 \mathrm{O} 5, \mathrm{MgO}, \mathrm{Al} 2 \mathrm{O} 3$, ve $\mathrm{CaF} 2$ bileşikleri kullanılmış ve ağıllıkça oranlarına göre tartım hesabı yapılarak bir karışım hazırlanmıştır. Hazırlanan bu karışım bir pota içerinde ergitilmiş ve işlem 1400 0C'nin üzerinde 1 saat boyunca gerçekleştirilmiştir. Ergimiş olan malzeme cam yapısı oluşturabilmek için grafit kalıplara dökülerek kritik soğuma hızının üzerinde soğutulmuştur. Elde edilen Apatit - Wollastonit'in içeriğini belirlemek amacıyla X-1şını floresans spektrometresi (XRF) analizi yapılmıştır. Numunelerden bir kısmına ise temperleme işlemi uygulanmış ve ölçülen mikrosertlik değerleri temperlenmeyen numuneler ile karşılaştırılmıştır. Bunlar dışında numunelerin taramalı elektron mikroskobu (SEM) ve enerji dağılımlı X-1şını spektroskopisi (EDS) analizleri de yapılmıştır. Deneyler sonucunda üretilen AW camının sertlik değerinin temperleme öncesi $370 \mathrm{Hv}$ olurken, temperleme sonrası ise $476 \mathrm{Hv}$ sertliğine ulaşıldığ görülmüştür. Yapılan SEM analizleri ise mikroyapının neredeyse porozitesiz olduğunu ortaya koymuştur.
\end{abstract}

Anahtar Kelimeler: Bioaktif, cam seramik, apatit-wollastonit, temperleme

\begin{abstract}
In this study, bioactive glass-ceramics containing apatite-wollastonite were produced and characterized. $\mathrm{CaO}, \mathrm{SiO}_{2}, \mathrm{P}_{2} \mathrm{O}_{5}, \mathrm{MgO}, \mathrm{Al}_{2} \mathrm{O}_{3}$, and $\mathrm{CaF}_{2}$ compounds were used for the production and a mixture was prepared by weight ratio. The prepared mixture was melted in a crucible and the process was carried out above $1400{ }^{\circ} \mathrm{C}$ for 1 hour. The molten glass was poured into the graphite mould form a crucible and supercooling was carried out. Then X-ray fluorescence spectrometry (XRF) analyses was performed to determine the content of apatite-wollastonite. The tempering was applied to some of samples and measured microhardness values compared with non-tempered samples. Furthermore, scanning electron microscopy (SEM) and energy dispersive X-ray spectroscopy (EDS) analyses were also investigated. In the result of experimental study, while before tempering the produced AW glass showed $370 \mathrm{Hv}$, heat treated the glass product had $476 \mathrm{Hv}$ value. SEM analyses revealed that the resulting glass had fairly pore-free microstructure.
\end{abstract}

Keywords: Bioactive, glass-ceramics, apatite-wollastonite, tempering

\section{Giriş}

Biyoaktif cam ve cam seramikler, kemik onarım uygulamalarında kullanılan doku onarım malzemeleri olup doku mühendisliği uygulamaları için geliştirilmiştir. Biyoaktif camlar amorf yapıya sahipken biyoaktif cam seramikler kristal yapı ve içerisinde kalıntı camsı fazı içeren bir

*Corresponding author: Address: Faculty of Technology, Department of Metallurgical and Materials Engineering, Sakarya University of Applied Sciences, 54187, Sakarya TURKEY. E-mail address: fcaliskan@sakarya.edu.tr, Phone: +902642956501 
kompozit yapıya sahiptir. Biyoaktif camlara ve onların biyomedikal uygulaması ve bilim dalına son 20 yilda giderek artan bir ilgi olmuştur [1-5].

Genel tanıma göre biyoaktif malzemeler spesifik biyolojik aktiviteyi geliştiren malzemler olarak tanımlanmaktadır [6]. Diğer bir tanıma göre, biyoaktif malzemeler, implante edildiği vücutla spesifik yüzey reaksiyonlarına giren malzemelerdir [7].

Bioaktif camlar, in vivo olarak yeni kemik dokusu oluşumunu desteklemektedir [88,89]. Tavşan femur kemiğine yapılan granül implantasyonu sonucunda, sentetik HA ile karşılaştırıldığında hızlı bir kemik proliferasyonun izlendiği kayda geçmiştir [8].

Günümüzde metal ve polimer esaslı malzemeler biyolojik uygulamalarda kullanılmaktadır. Bununla birlikte seramik teknolojisinde yaşanan gelişmeler bize bu malzemelerin yüksek mekanik güç ve iyi biyouyumluluk sağladığını göstermiştir. Bu seramikler arasında yer alan apatit vollastonit cam seramikler ise diğer biyomalzemelere göre daha iyi mekanik özelliklere sahip olduğundan çalışmada tercih edilmiştir. Bu durum Tablo 1'de gösterilmiştir [9].

Tablo 1. Biyomalzemerin mekanik özelliklerinin karşılaştırılması [9]

\begin{tabular}{ccc}
\hline & $\begin{array}{c}\text { Eğme } \\
\text { Mukavemeti } \\
(\mathrm{MPa})\end{array}$ & $\begin{array}{c}\text { Kirılma } \\
\text { Tokluğu }\left(\mathrm{K}_{\mathrm{IC}}\right) \\
(\mathrm{MPa} / \mathrm{m})\end{array}$ \\
\hline Cam & 70 & 0.8 \\
Hidroksiapatit & 115 & 1 \\
Apatit-wollastonit & 200 & 2 \\
İnsan kemiği & 160 & $3-6$ \\
\hline
\end{tabular}

Tablodan da görüleceği üzere apatit wollastonitin eğme mukavemeti diğerlerinden çok daha iyi durumdadır. Ayrıca mevcut çalışmalar apatit wollastonitin kemiklerle kuvvetli kimyasal bağ yapabildiğini bize göstermiştir. Çalışmada bu malzemenin hazırlanması ve karakterizasyonundan bahsedilecektir.

\section{Materyal ve Metot}

Apatit wollastonit üretimi için, >\% 99 saflıkta $\mathrm{CaO}, \mathrm{SiO}_{2}, \mathrm{P}_{2} \mathrm{O}_{5}, \mathrm{MgO}, \mathrm{Al}_{2} \mathrm{O}_{3}$, ve $\mathrm{CaF}_{2}$ bileşikleri kullanılmış ve ağırlıkça oranlarına göre tartım hesabı yapılarak bir karışım hazırlanmıştır. Apatit kristalleri içeren wollastonit üretimi ve optimum kompozisyon Kokubo tarafından ilk olarak bulunmuştur. Hazırlanan bu karışım alümina pota içerinde ergitilmiş ve işlem $1400{ }^{0} \mathrm{C}^{\prime}$ nin üzerinde 1 saat boyunca gerçekleştirilmiştir. Ergimiş haldeki cam yapısının oda sıcaklığında koruyabilmek için yani katı formda cam elde edebilmek için grafit kalıpların içerisinde hızla soğutulmuştur. Daha sonra hassas kesme cihazında kesilen numuneler kontaminasyon olmamas1 için halkalı değirmende ögütülerek toz formuna getirilerek XRF analizinde kullanılmıştır. 
Numuneler iki set halinde hazırlanmıştır. İlk set ergitme yöntemiyle grafit kalıba dökülerek elde edilen numunelerken, ikinci set ise aynı şartlarda üretilip sonrasında $700^{\circ} \mathrm{C}$ 'nin üzerinde temperlenen numunelerden oluşmuştur.

\section{Sonuçlar ve Tartışma}

Karakterizasyon için üretilen bar şeklindeki AW numuneleri kullanılmıştır.

\subsection{X-ışını Floresans Spektrometresi (XRF) Analizi}

Üretilen malzemenin ilk olarak X ışını kırınımı ile içerisindeki oksitler ve miktarları karakterize edilmiştir. Literatürde verilen AW kompozisyonu ile bu çalışmada üretilen numunelerin toz halde yapılan XRF sonuçları karşılaştırılmıştır. Tablo 2'de verilen XRF sonuçları incelendiğinde orijinal değerlerle karşılaştırıldığında neredeyse aynı sonuçları vermiştir. $\mathrm{CaO}, \mathrm{SiO}_{2}$ ve $\mathrm{P}_{2} \mathrm{O}_{5}$ temel bileşenlerdir. X ışını kırınım (XRF) için oluşturulan numune hazırlama aşamasında 9 gr A$\mathrm{W}$ tozu ile 1 gr wax bağlayıcı karıştırılmıştır.

Tablo 2. A-W gerçek kompozisyonu ile üretilen malzemenin kompozisyonu.

\begin{tabular}{ccccccc}
\hline $\begin{array}{c}\text { Kompozisyon } \\
(\%)\end{array}$ & $\mathrm{SiO}_{2}$ & $\mathrm{P}_{2} \mathrm{O}_{5}$ & $\mathrm{CaO}$ & $\mathrm{CaF}_{2}$ & $\mathrm{Al}_{2} \mathrm{O}_{3}$ & $\mathrm{MgO}$ \\
\hline $\begin{array}{c}\text { Gerçek } \\
\text { kompozisyon } \\
\text { XRF sonucu }\end{array}$ & 33,75 & 13,48 & 48,86 & 0,03 & 1,9 & 1,94 \\
\hline
\end{tabular}

\subsection{SEM ve EDS Sonuçları}

Kritik soğuma hızının üzerinde soğutularak kristalizasyon oluşmadan elde edilmeye çalışılan numunelerin mikro yapılarını görüntülemek amacıyla taramalı elektron mikroskobu görüntüsü alınmıştır. Numuneler metalografik işlemlerle hazırlanarak mikroyapı incelemesine uygun hale getirilmiştir. Şekil 1'de A-W biyoaktif cam malzemenin taramalı elektron mikroskobu görüntüsü verilmiştir. 


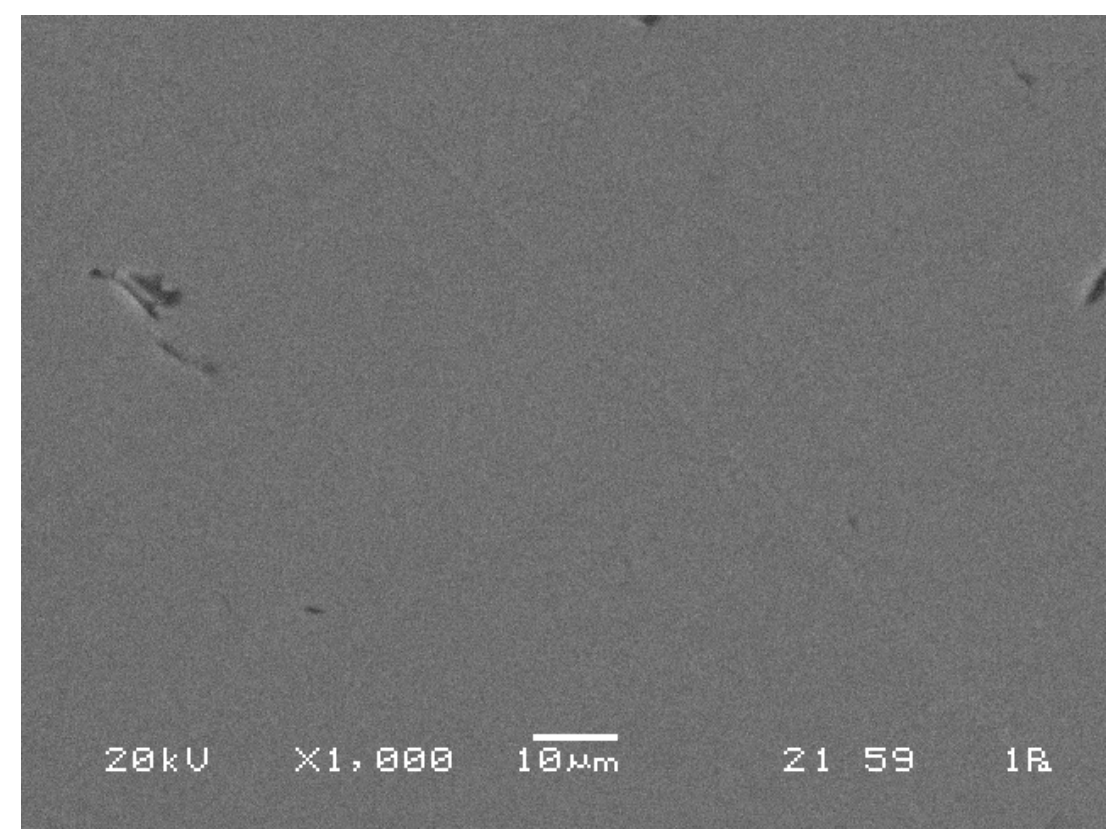

Şekil 1. A-W biyomalzemenin taramalı elektron mikroskobu görüntüsü

Şekilde görüldüğü üzere oluşan poroziteler ortalama 2 mikron ile 8 mikron arasında değişmektedir. Görünen beyaz kısmı ise cam fazı oluşturmaktadır. Buradan da tahmin edilebileceği üzere malzememizde porozite miktarı oldukça düşüktür. Üretilen AW cam numunelerin yoğunluklarının oldukça yüksek olduğu görülmektedir.

Numunenin içerisinde yer alan elementlerin analizi ve miktarları da elementel (EDS) analizi ile desteklenmiştir. Şekil 2'de bu durum gösterilmiştir.

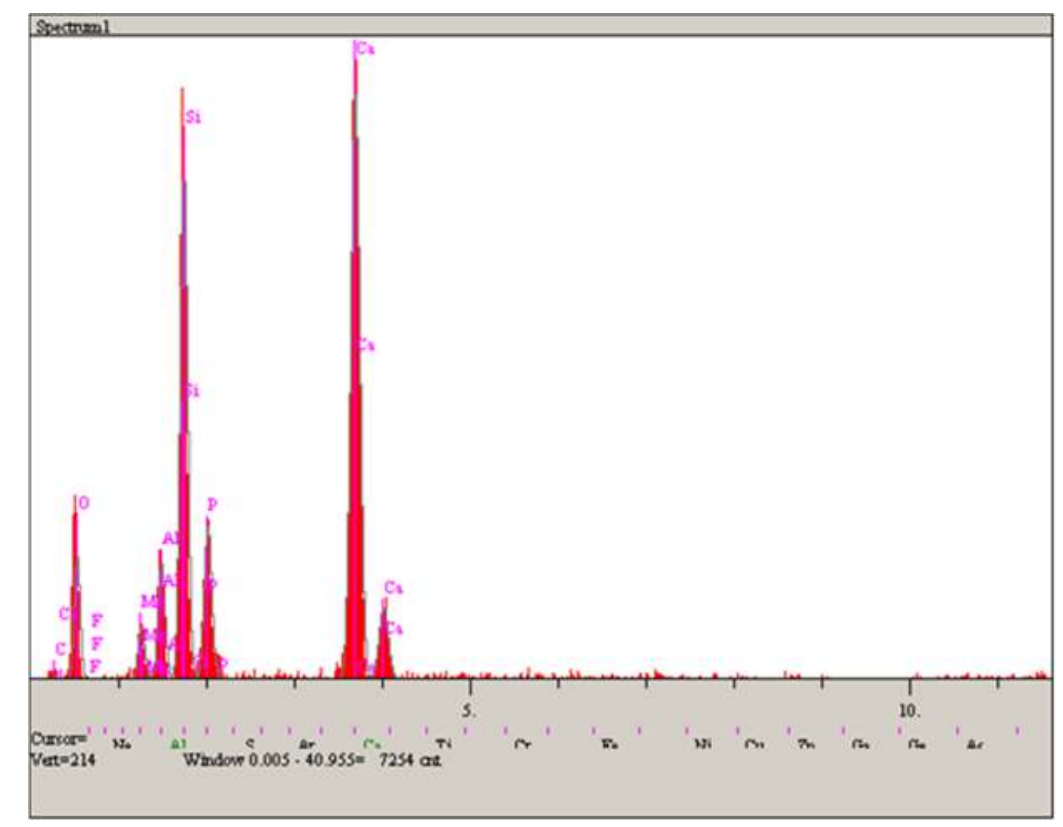

Şekil 2. A-W cam numunelerinin elementel analizi 
Şekilde taramalı elektron mikroskobu ile çekilen bölgeden yapılan elementel analizde görüldüğü üzere numunede, kompozisyon hazırlanmasında sırasında toz karışımına konulan bileşim ve oranlarının elementel bazda neredeyse aynı olduğu tespit edilmiştir. Tablo 3'te ise bu elementlerin ağırlıkça yüzdeleri görülmektedir. $\mathrm{Ca}, \mathrm{P}, \mathrm{Si}, \mathrm{Al}, \mathrm{Mg}, \mathrm{F}$ ve $\mathrm{O}$ başlangıç kompozisyonundaki elemenlerdir. Ağ.\% 0.731 oranındaki $\mathrm{C}$ analiz sırasında kullanılan karbon altlıktan gelen kirlenmedir.

Tablo 3. EDS ile tespit edilen elementlerin ağırlıkça oranları (ağ.\%)

\begin{tabular}{|l|l|l|l|l|l|}
\hline Elt. & Çizgi & Şiddet (c/s) & Hata 2-sig & Sonuç & Birim \\
\hline $\mathrm{C}$ & Ka & 0.57 & 0.475 & 0.731 & ağ.\% \\
\hline $\mathrm{O}$ & Ka & 35.23 & 3.753 & 33.902 & ağ.\% \\
\hline $\mathrm{F}$ & $\mathrm{Ka}$ & 0.05 & 0.144 & 0.041 & ağ.\% \\
\hline $\mathrm{Mg}$ & $\mathrm{Ka}$ & 16.69 & 2.583 & 2.290 & ağ.\% \\
\hline $\mathrm{Al}$ & $\mathrm{Ka}$ & 38.62 & 3.929 & 4.626 & ağ.\% \\
\hline $\mathrm{Si}$ & Ka & 175.93 & 8.387 & 19.498 & ağ.\% \\
\hline $\mathrm{P}$ & Ka & 54.39 & 4.663 & 7.344 & ağ.\% \\
\hline $\mathrm{Ca}$ & Ka & 248.94 & 9.976 & 31.568 & ağ.\% \\
\hline & & & Toplam & 100.000 & ağ.\% \\
\hline
\end{tabular}

\subsection{Mekanik Özelliklerin Tespiti}

Mekanik özelliklerin tespiti için mikro Vickers yöntemiyle sertlik ölçümü yapılmıştır. Bu yöntemde 50 gr yük altında numunelerin sertliği ölçülmüştür. Sertlik ölçüm testi, ürünlerin sertlik seviyeleri karşılaştırma yapmak amaciyla hem temperlenmiş hemde temperlenmeden üretilen numuneler için gerçekleştirilmiştir. Şekil 3'te verilen sertlik ölçüm sonuçları incelendiğinde, temperlenmemiş bir numune için ortalama ölçüm değeri $370 \mathrm{Hv}$ civarlarında olduğu tespit edilmiştir. Karşılaştırma yapmak için üretilen $700^{\circ} \mathrm{C}$ üzerinde temperleme işlemine tabi tutulan numunenin sertlik değeri ise ortalama $\sim 476 \mathrm{Hv}$ olarak ölçülmüştür. $\mathrm{Bu}$ sonuçlardan da anlaşılacağı gibi temperleme işlemi mekanik özellikler üzerinde yaklaşık \%30'luk net bir artış sağlamıştır. Temperlenen A-W cam malzemesiyle ulaşılan mikrosertlik değeri ( $476 \mathrm{Hv})$ Tablo 4 'te sertlik değerleri verilen hidroksiapatit, insan kemiği ve temperlenmemiş AW ile bu çalışmada elde edilen en yüksek değeri elde edilen temperlenmiş AW camı ile karşılaştırıldığında temperlenmiş AW camının sertlik değerinin hepsinde yüksek olduğu görülmektedir. Buda bu çalışmada üretilen numunelerin, mekanik özellikler açısından biyolojik malzeme olarak kullanılabilir olduğunu göstermektedir. 


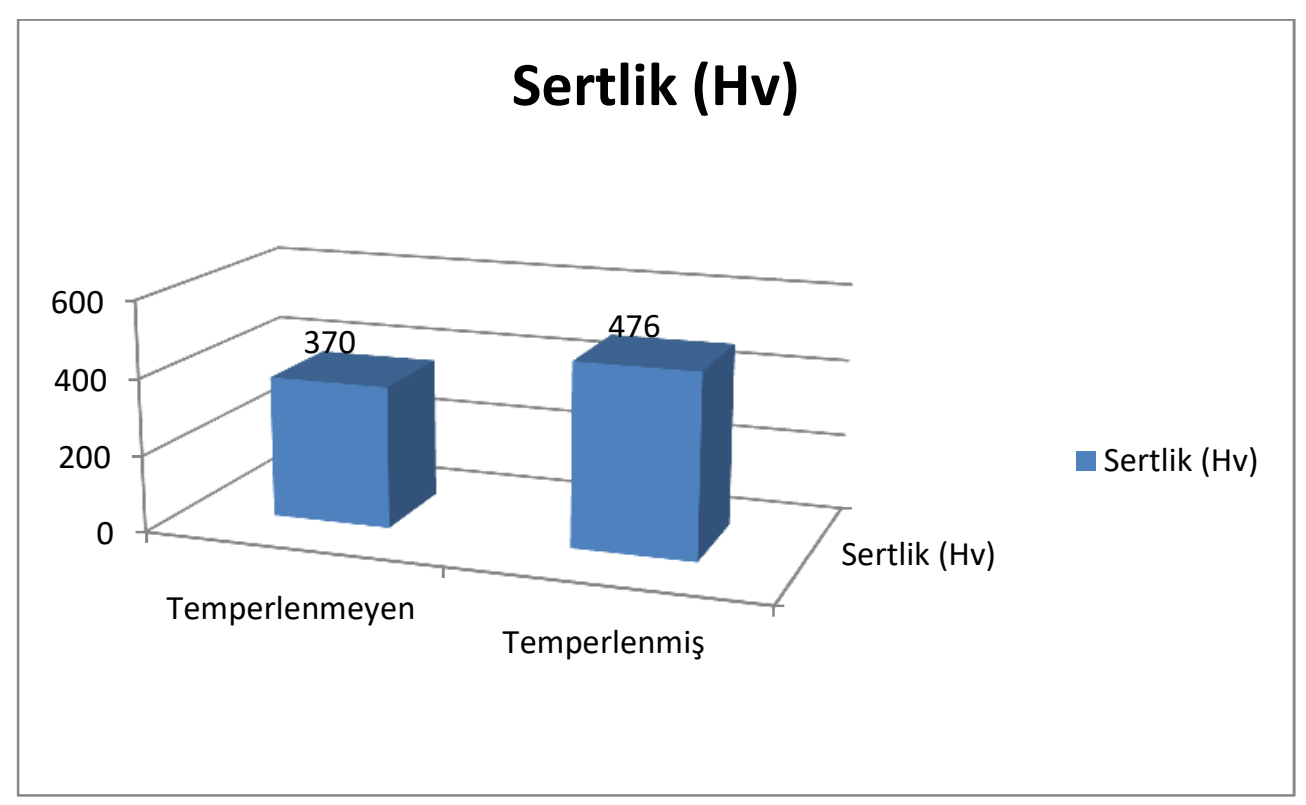

Şekil 1. Temperlenen ve temperlenmemiş numunenin sertlik değerlerinin karşılaştırılması

Tablo 4'te diğer biyoseramiklere oranla sertliklerinin karşılaştırması verilmiştir.

Tablo 4. Biyoseramiklerin sertliklerinin karşılaştırılması

\begin{tabular}{cc}
\hline Malzeme & Sertlik (Hv) \\
\hline Hidroksiapatit & $350[3]$ \\
Temperlenmemiş A-W & 370 \\
Temperlenmiş A-W & 476 \\
İnsan Kemiği & 420
\end{tabular}

Referansta verilen megapaskal (MPa) cinsinden olan sertlik değeri Vickers'e dönüştürülmüştür [10-11-13]

\section{Tartışma}

$\mathrm{Bu}$ çalışmada Cam ergitme metodu kullanılarak literatürde AW cam seramik üretimi için kullanılan kompozisyon ile AW bileşenlerini içeren kristallenmemiş cam ürünlerin üretimi başarılmıştır.

Elde edilen sonuçlar irdelendiğinde temperlenen numunenin sertliğinde yaklaşık \%29 oranında bir gelişme olduğu görülmüştür. Bununla birlikte isıl işlem sıcaklığında az miktarda kristalizasyon kaçınılmaz olmuştur.

Deneysel veriler incelendiğinde apatit-wollastonitin mekanik özelliklerinin mevcut biyomalzemelerden daha iyi olduğu görülmektedir. Literatür araştırmaları da bize bu malzemenin 
mevcut diğer malzemelere oranla insan vücuduna uyum sağlama özelliğinin çok daha iyi olduğunu söylemektedir. [12]. Ayrıca A-W'nin bilinen herhangi bir toksik etkisi de bulunmamaktadır.

Taramalı elektron mikroskobu analizleri döküm ergitme yöntemiyle üretilen numunenin iç yapısının neredeyse gözeneksiz bir mikroyapıya sahip olduğunu göstermiştir.

Cam yapısının başarıyla elde edildiğinin en önemli göstergesi transparan özelliğinin korunmasıdır. Bu çalışmada ergitme sonucu kalıplanan numunelerin kritik soğuma sıcaklığını kesmeden başarıyla cam formuyla üretilebildiği ortaya konmuştur.

\section{Referanslar}

[1] Hench LL, Wilson J. Surface active biomaterials. Science 1984;226:630-6.

[2] Yamamuro T, Hench LL, Wilson J, editors. Handbook of bioactive ceramics, vols. 1 and 2. Boca Raton, FL: CRC Press; 1990.

[3] Hench LL. Bioceramics. J Am Ceram Soc 1998;81:1705-28.

[4] Rahaman MN, Brown RF, Bal BS, Day DE. Bioactive glasses for non-bearing applications in total joint replacement. Semin Arthroplasty 2007;17:102-12.

[5] Williams DF, editor. Definitions in biomaterials. New York: Elsevier; 1987.

[6] Williams DF, editor. Definitions in biomaterials. New York: Elsevier; 1987.

[7] Kokubo T, Takadama H. How useful is SBF in predicting in vivo bone bioactivity? Biomaterials 2006;27:2907-15.

[8] Oonishi H, Hench LL, Wilson J, Sugihara F, Tsuji E, Kushitani S, et al. Comparative bone growth behavior in granules of bioceramic materials of various sizes. J Biomed Mater Res 1999;44:31-43.

[9]. Kokubo Tadashi, "Bioactive glass ceramics: properties and applications", Institute for Chemical Research, Kyoto University. Presented at Biomteractions '90, Oxford, UK 21-23 August 1990.

[10]. Timuçin, M. Öztürk, A. Korkusuz, F. et al., Apatit - Wollastonit Biyoaktif Seramiklerin Üretimi ve Karakterizasyonu, Proje No: 104M400, Ortadoğu Teknik Üniversitesi, Ankara, Mayıs 2008.

[11]. Fan, ZF, Smith, PA, Harris, GF, Mechanical Properties of OI Type III Human Bone Tissue Measured by Nanoindentation, 51st Annual Meeting of the Orthopaedic Research Society, Paper No: 0030 .

[12]. Kokubo T. Shigematzu M., et al., "Apatite- and Wollastonite-Containg Glass-Ceramics for Prosthetic Application”, Bull. Inst. Chem. Res., Kyoto Univ., Vol. 60, No. 3-4, 1982

[13]. Mohamed N. R., et al., Bioactive glass in tissue engineering, Acta Biomaterialia, 7 (2011) $2355-2373$. 